\title{
Mabel Assis, uma rosa negra semeando a primavera
}

\author{
Renata Gonçalves* \\ Magali da Silva Almeida**
}

Nas primeiras horas de dezembro de 2019, Mabel Isabel de Assis, nossa Mabel Assis, passou à condição de ancestral. Ela, que sempre foi nosso porto seguro, nossa fortaleza no combate ao racismo e à violência patriarcal, fez a passagem para ocupar um lugar majestoso reservado às deusas no Orun, deixando-nos a lembrança de seu sorriso largo e acolhedor. No interior do Serviço Social, era nossa referência no que tange à introdução de autores/ as negros/as e uma bibliografia especializada sobre relações étnico-raciais no processo de formação da categoria. Com ela, aprendia-se sobre as mazelas do racismo à brasileira, institucionalizado e naturalizado, que teimam em controlar e cada vez mais em aniquilar vidas negras. Vinha dela o esforço diário de discutir a dinâmica racial no exercício da profissão. Mabel refletia pura vivacidade. Era um espelho em que nós, sobretudo as mulheres negras, nos reconhecíamos. Num mesmo movimento, também nutríamos por ela uma profunda admiração. E não podia ser diferente. A dona do riso solto, do andar faceiro, da voz firme e imponente teve uma trajetória de vida semeIhante à de muitas mulheres negras, não fosse sua irreverência. $O$ traço rebelde de nossa flor de ébano a fez trilhar caminhos distintos até a encruzilhada, que se tornou ponto de partida (ou ponto de encontro) teórico e político com (e para) muitas de nós. Mas como ela chegou até lá, até aqui, até nós?

Mabel Assis é a décima filha de pai e mãe que apenas sabiam assinar o nome. Fugindo da violência dos coronéis das terras de Minas Gerais, a família largou tudo e se instalou na Brasilândia, uma das regiões periféricas mais empobrecidas da cidade de São Paulo. Dos catorze filhos, treze sobreviveram. A história se repetia para a família de Mabel como reflexo direto

\footnotetext{
* É Assistente Social formada pelo Institut Cardjin, Bélgica; mestre e doutora em Ciências Sociais respectivamente pela PUC-SP e pela Unicamp. É docente do curso de Serviço Social e do Programa de Pós-graduação em Serviço Social e Políticas Sociais da Universidade Federal de São Paulo, campus Baixada Santista, onde coordena o Núcleo de Estudos Reflexos de Palmares e o Núcleo de Estudos Heleieth Saffioti. E-mail: rengon2011@gmail.com. ORCID: https://orcid.org/0000-0002-2470-9095.

**É assistente Social e doutora em Serviço Social pela PUC do Rio de Janeiro. Professora do curso de Serviço Social e Coordenadora do Programa de Pós-Graduação em Serviço Social do Instituto de Psicologia da Universidade Federal da Bahia. Coordena o Observatório de Racialidade e Interseccionalidade ORI- Núcleo de Pesquisa e Extensão sobre relações raciais, de gênero e classe e lutas sociais antirracistas. E-mail: quilombola_rio56@ yahoo.com.br.
} 


\section{Revilgto am palth}

\} MABEL ASSIS, UMA ROSA NEGRA - GONÇALVES, R.; ALMEIDA, M. S. \}

DOI: $10.12957 /$ REP.2020.47193

do racismo nas famílias negras, em especial na vida das mulheres negras. Diante da impossibilidade do emprego formal, restavam à sua mãe os precários empregos de faxineira, lavadeira, cozinheira. Certamente, um resquício incrustrado da violência da casa grande.

A condição das mulheres negras guarda estreita relação com o passado escravista, com a organização patriarcal e com a exploração capitalista de classe. Sob o capitalismo, tanto o racismo como o sexismo se tornaram parte de uma engrenagem que reforça desigualdades que, num círculo virtuoso, retroalimentam o sistema do capital. Lélia Gonzalez (2018) examinou a neurose da cultura brasileira e criticou a divisão sexual e racial do trabalho em que a "mulher negra, naturalmente, é cozinheira, faxineira, servente, cobradora de ônibus ou prostituta". A autora indaga: "Por que será que ela só desempenha atividades que não implicam em 'lidar com o público'? Ou seja, em atividades onde não podem ser vistas? Por que os anúncios de emprego falam tanto em 'boa aparência'?"(GONZALEZ, 2018, p. 202). E o que significa ter uma boa aparência? O valor da brancura na sociedade do capital assume contornos inimagináveis para eliminar quem dele se distancia.

Foi assim que o racismo também tentou empurrar nossa rosa negra para a invisibilidade. Desenvolta, foi indicada por um vizinho para um trabalho como ascensorista, um posto que a colocaria em contato com muitas pessoas. Era seu primeiro emprego e, logo na chegada, a puseram nos porões da faxina. Ela insistiu mais dois dias para ter certeza de que não era um engano da empresa. Irreverente, não aceitou ser invisível. Naquele emprego, descobriu um pouco mais sobre os tentáculos do racismo e aprendeu com a mãe que, se não gostava de obedecer a ordens e nem de limpar, teria de estudar muito.

Apesar da infância na pobreza, Mabel fazia questão de relatar que foi imensamente feliz. O pai, que não sabia ler nem escrever, tocava violino e cavaquinho como ninguém. Sem dinheiro suficiente para comprar uma televisão (o que a maioria dos lares almejava), a família transformava as noites em momentos de música. A mãe, que também tinha seus dons artísticos, tocava violão e cantava. Cuidadosa, explicou aos filhos que aquelas músicas tocadas em casa, jamais poderiam ser cantadas em outro ambiente. Só mais tarde Mabel compreendeu o contexto e percebeu que a restrição era para protegê-los da violência da ditadura militar. Sua família encontrou na música uma maneira de resistir e manter as memórias e as histórias coletivas. E assim nossa querida amiga foi sendo educada para a vida. Naqueles momentos, sentavam-se à volta do fogão de lenha e a mãe ia cantando, ia contando os "causos", como manda a tradição oral da ancestralidade africana.

Educar para a vida não substituía a educação formal que, aos olhos de sua família, possibilitaria que as filhas e filhos ascendessem socialmente ou ao menos permitiria que saíssem da invisibilidade dos postos de subserviência. Porém, no ambiente escolar Mabel viveu suas primeiras experiências 


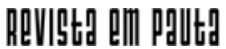

\} MABEL ASSIS, UMA ROSA NEGRA - GONÇALVES, R.; ALMEIDA, M. S. \}

DOI: $10.12957 /$ REP.2020.47193

dolorosas com o racismo. Professores que deveriam acolhê-la como qualquer criança, ao contrário, incitavam estudantes a puxarem seus cabelos. A cada dia, a escola se tornava um lugar insuportável e seu maior pavor era a palmatória, não pela dor física que sentiria, mas pela reação que sabia que poderia ter, pois jamais toleraria tamanha violência e seu senso de justiça com certeza a levaria a revidar. O temor se justificava pelo fato de seu pai ter conseguido um emprego de jardineiro na escola onde ela estudava e, portanto, ser demitido por causa de algum revide da filha. Ela também não contava para a mãe, pois sabia que esta não pensaria duas vezes para defender a filha e que o professor corria um sério risco de levar uns tabefes. Numa família empobrecida é preciso se agarrar à única fonte de sustento.

Mais tarde, compreendeu que não era a única a sofrer aquela violência. Encontrou duas colegas de escola e soube que uma foi expulsa porque resistiu às ofensas racistas, a outra se evadiu porque não suportou a dor do racismo (ASSIS, 2018). Ainda hoje são muitos os relatos de crianças que sofrem com o racismo nas escolas, nunca são acarinhadas por serem negras, nunca recebem um elogio porque não correspondem ao modelo ideal da brancura. Uma prática que remonta ao período da escravidão em que a criança negra era tratada como um adulto negro em miniatura e desde os 67 anos de idade está apto ao trabalho e podia receber castigos físicos como forma de correção (MATTOSO, 1988). A passagem para o capitalismo não alterou esta maneira de perceber as crianças negras, isto é, apenas aptas para o mundo do trabalho. A educação escolar para estas crianças nunca foi um projeto para o país, o que cotidianamente leva muitas crianças a desistirem de estudar.

O ambiente escolar de nossa rosa azeviche foi marcado por símbolos da brancura, que iam da valorização das crianças brancas por meio dos elogios e afagos à forma como os personagens negros eram retratados nos livros escolares. A cartilha de alfabetização Caminho Suave', de Branca Alves de Lima, adotada nas escolas públicas brasileiras desde 1948, é um grande exemplo ao qual Mabel sempre se referiu. O livro se baseia na imagem como metodologia para alfabetizar as crianças. Logo na capa, percebíamos uma menina loira e um garoto alvíssimo, muito bem vestidos, a caminho da escola. E o que dizer do interior do livro, quando nos deparávamos com a imagem de uma mulher negra com balde na mão e sujeira no rosto? Este lugar, a nossa rosa livre não quis ocupar. Como não havia em quem se espelhar, ela furou o bloqueio e se tornou o próprio espelho. O que não foi muito fácil.

Sua entrada no ginasial ${ }^{2}$ também foi marcada pelas dificuldades que a classe trabalhadora enfrenta para alçar voos. À época, havia um exame de admissão a ser feito e era pago. Nossa Mabel simplesmente não tinha di-

\footnotetext{
1 Foi o livro oficial de alfabetização do Ministério da Cultura por quase cinquenta anos, com mais de 40 milhões de exemplares impressos em quase 150 edições; só deixou de ser o instrumento oficial de alfabetização do país em 1995, embora muitos exemplares continuem sendo vendidos (GARCIA, 2017).

${ }^{2}$ Correspondente hoje ao Ensino Fundamental II.
} 


\section{Revilgto am palth}

\} MABEL ASSIS, UMA ROSA NEGRA - GONÇALVES, R.; ALMEIDA, M. S. \}

DOI: $10.12957 /$ REP.2020.47193

nheiro para pagar. Com a ajuda da irmã, conseguiu entrar numa escola e a contrapartida seria limpá-la aos sábados. Assediada sexualmente pelo dono do ginásio, que como muitos homens acham que o corpo das mulheres negras são disponíveis, reagiu e foi expulsa. Parou de estudar por muito tempo, só voltando aos bancos escolares quando o ensino foi democratizado.

Concluiu o ginásio e precisava fazer o $2^{\circ}$ grau (hoje, Ensino Médio), que também não era acessível. Teria de fazer o Vestibulinho e lidar com todos os entraves que dificultavam o acesso de filhos e filhas de trabalhadores/ as, sobretudo pretos/as. Estava desistindo quando a encruzilhada da vida possibilitou o encontro com um amigo preto que fazia faculdade. Aquele encontro mudou sua percepção. Ela não desistiu e resolveu fazer o segundo grau numa escola particular, com um bom emprego que acabara de conseguir, poderia pagar.

A irmã, muito atuante no movimento negro, foi responsável por convencer Mabel da importância de estudar as relações étnico-raciais e compreender as entranhas do racismo na nossa sociedade. As experiências dolorosas advindas da condição de ser negra deixaram feridas que Mabel resistia em abrir. Convenceu-se, sob os sólidos argumentos da irmã, que era preciso encarar o racismo de frente. A partir de então, outras oportunidades se abriram. Frequentou o cursinho preparatório para o Vestibular no Instituto Negro Padre Batista, fruto da parceria de Frei Davi com a PUC-SP, que ganhou o carinhoso apelido de Quilombo Central. Teve contato com o que havia de melhor em termos de estudos afro-brasileiros. As cartilhas eram preparadas pela grande educadora Petronilha Beatriz Gonçalves e Silva, que mais tarde seria a relatora do Parecer CNE/CP 3/2004, que estabelece as Diretrizes Curriculares Nacionais para a Educação das Relações ÉtnicoRaciais e para o Ensino de História e Cultura Afro-Brasileira e Africana.

Depois de compreender o funcionamento do racismo no Brasil, Mabel quis fazer o curso de Direito porque entendeu que seria necessário mexer na base das leis do país. Sabia da desigualdade e da violência contra trabalhadores/as negros/as, mas ainda não conseguia entender todos os seus mecanismos e achou que as matrizes curriculares do Direito possibilitaria esta percepção. No entanto, o elitismo desta área de conhecimento impediu seu acesso. Resolveu se preparar um pouco mais. Tentou fazer o cursinho popular da Poli. Embora popular, havia uma nota de corte e Mabel, de novo, disputando com filhas/os da classe média, ficou de fora. O racismo sempre se traveste de legalidade para se legitimar. $\mathrm{O}$ valor da brancura se camufla facilmente em meritocracia. Tentou outro cursinho, mas como seria possível, no meio de 400 pessoas, conhecer tudo e em tão pouco tempo o que não havia aprendido ao longo da vida? Decidida, foi se preparar. Saiu do cursinho e fez o segundo grau novamente. Assistia ao telecurso, lias revistas, dialogava com a irmã, com amigas/as. Passou no vestibular unificado da PUC-SP. Mas, o que não era exatamente uma novidade, não atingiu os pontos necessários para o elitizado curso de Direito. 


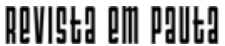

\} MABEL ASSIS, UMA ROSA NEGRA - GONÇALVES, R.; ALMEIDA, M. S. \}

DOI: $10.12957 /$ REP.2020.47193

Esta nova encruzilhada que fechava o caminho para o curso de Direito, abria definitivamente nossa rosa negra para o Serviço Social. Mabel queria compreender e mudar a estrutura da sociedade e tinha dúvidas se a partir desta profissão conseguiria. Pronta a encarar mais um desafio, se matriculou no curso de Serviço Social. Para ela, foi a partir daí que começou a entender como funciona a sociedade, as relações sociais e a produção da desigualdade no capitalismo. Foi também no curso de Serviço Social que outros caminhos foram apontados por algumas professoras que à época falavam da importância de Mabel discutir gênero e raça. Alguém precisava dar esse pontapé e o Serviço Social precisava olhar para a imbricação das relações de gênero e étnico-raciais com o capitalismo. Nunca se esqueceu do presente recebido das mãos da diretora do curso. Foi seu primeiro livro sobre a temática racial: O significado do protesto negro, de Florestan Fernandes. Aquela obra foi a porta de entrada para entender teoricamente o racismo. Nas memórias de nossa rosa azeviche (ASSIS, 2019), relata que também contou com a ajuda de Matilde Ribeiro, que já era uma referência no movimento negro.

Desde então, seus estudos a ajudaram a compreender que o destino de trabalhadores/as negros/as no Brasil está dado em função da cor da pele, uma das manifestações mais fortes do racismo, que faz com que o potencial de uma pessoa negra nem seja observado. É a pessoa como um todo que nem é notada, não é vista, não é levada em consideração, sendo arrancada dela qualquer capacidade intelectual, ficando invisibilizada e sem oportunidade de mudar esta situação.

Suas pesquisas de graduação a levaram a escrever um Trabalho de Conclusão de Curso sobre a temática racial, mais precisamente a respeito das mulheres negras. Ali se definiu seu lugar no debate sobre o racismo no Brasil. Num diálogo com o livro de Ricardo Antunes, Adeus ao trabalho?, problematizou o lugar reservado às trabalhadoras negras na chamada reestruturação produtiva do capital, um debate cada vez mais discutido na atualidade do precariado brasileiro. O entusiasmo da banca foi tão grande que a jovem pesquisadora se lançou imediatamente no processo seletivo do mestrado. Passou pela difícil fase da prova teórica, mas no momento da entrevista esbarrou em uma banca que considerou que nossa intelectual azeviche precisava voltar para a prática porque não queriam pessoas teóricas. Ora, Mabel a esta altura de sua formação já havia passado pela prática nos estágios, no trabalho nas comunidades, especialmente por meio de sua atuação no Geledés - Instituto da Mulher Negra e depois na Fala Preta - organização de mulheres Negras ${ }^{3}$, que discutia estratégias de emancipação e de ruptura com as situações que as mulheres negras vivenciavam em decorrência do racismo. Talvez a dificuldade da banca em reconhecer o racismo como fundamental na dinâmica da reprodução do capital, tenha impedido que

${ }^{3}$ Dissidente do Geledés em 1997. Referência em termos de coletivos de mulheres negras em São Paulo. 


\section{Revilgto am palth}

\} MABEL ASSIS, UMA ROSA NEGRA - GONÇALVES, R.; ALMEIDA, M. S. \}

DOI: $10.12957 /$ REP.2020.47193

Mabel entrasse no mestrado. Do contrário, como explicar que outras colegas, que fizeram a mesma seleção com projetos bem mais teóricos, não receberam aquele tipo de instrução?

Explicitava-se mais uma vez a divisão racial do trabalho, que reserva aos negros, sobretudo às mulheres negras, os degraus inferiores da sociedade e só lhes é permitido ocupar os mesmos espaços de brancos/as apenas na condição de servi-los/as (GONZALEZ, 2018). Nesta divisão racial, muIheres negras definitivamente não são pesquisadoras acadêmicas e quando conseguem romper as barreiras raciais, com frequência, são lembradas de que estão fora de seus lugares. Esta é a lógica do "patriarcado capitalista com supremacia branca", como escreve bell hooks (1995, p. 468), em que a cultura age para impossibilitar que as mulheres, sobretudo as negras, atuem enquanto intelectuais que exercitam de forma criativa suas mentes. $\mathrm{Na}$ perspectiva de hooks, racismo e sexismo "incutiram na consciência de todos a ideia de que as negras eram só corpo sem mente" (1995, p. 469).

A porta que se abriu para Mabel foi a da Antropologia, onde conseguiu aprofundar suas pesquisas sobre o racismo. Curiosamente, a PUCSP é uma referencia nos estudos sobre relações étnico-raciais em várias áreas do conhecimento, mas não no Serviço Social. Até muito recentemente, não havia produção sólida sobre questão racial na área, não havia docentes discutindo a temática ou com produção teórica de fôlego e muito menos um diálogo sobre o assunto, o que, aliás, permanece muito tímido. Ainda é difícil a categoria perceber que o racismo é intrínseco à questão social ou mesmo que a questão racial antecede a questão social no Brasil (GONÇALVES, 2018). O que dificulta compreender, inclusive, a institucionalização do racismo em todos os poros de nossa sociedade, fazendo com que, mesmo nos espaços que se consideram os mais progressistas, haja manifestações racistas. E o Serviço Social, apesar de seu projeto ético-político de defesa dos/as trabalhadores/as não está imune à prática do racismo, que se manifesta em salas de aulas, em expressões utilizadas por docentes, entre colegas, nos espaços dos estágios, na intervenção profissional etc. Sem contar que é negra a grande maioria de usuários/as dos serviços de atendimento de profissionais Assistentes Sociais. E isto não é fruto do acaso, mas sim de uma estrutura social que combina violência de gênero e racismo para melhor reproduzir o capital.

Introduzir os estudos das relações étnico-raciais e o ensino de história e cultura afro-brasileira e africana nas matrizes curriculares dos cursos de Serviço Social é uma tarefa das mais urgentes. Parafraseando Edna Roland, sua amiga e grande referência intelectual do movimento negro, Mabel dizia que o racismo precisa tocar mentes e corações; é leitura obrigatória de todo o coletivo.

Para ela, os espaços precisam ser representativos dos segmentos populacionais. A universidade precisa ser o lugar para o diverso e a produção do conhecimento não pode ser um patrimônio branco. Em sua concepção, 


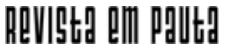

\} MABEL ASSIS, UMA ROSA NEGRA - GONÇALVES, R.; ALMEIDA, M. S. \}

DOI: $10.12957 /$ REP.2020.47193

foi o privilégio da brancura que impediu seu ingresso no mestrado em Serviço Social. É a brancura que insiste que o lugar do negro na academia é somente como objeto de pesquisa e não como sujeito que pesquisa.

Como intelectual negra, encarou o mestrado em Antropologia como mais uma luta coletiva. Trabalhando como Assistente Social, conseguiu ampliar sua visão sobre o racismo institucional e a estrutura patriarcal que violenta diariamente as mulheres negras. Fez desse trabalho seu tema de pesquisa: mulheres negras e violência doméstica. Estudiosa do assunto, compreendeu que as violências não eram apenas físicas. Enquanto Assistente Social buscou construir novas ferramentas tanto para lidar com a violência como para ajudar as mulheres a tomarem consciência de que eram vítimas e como deveriam agir, quais mecanismos acionar. $\mathrm{O}$ fato de suas mães e avós terem passado por experiências semelhantes, dificultava a compreensão de que estavam em relações abusivas. Pior, a naturalização do poder do macho, como escrevia Heleieth Saffioti (1987), fazia com que se sentissem culpadas por sofrerem a violência. Não era (e não é) incomum ouvir "o que foi que eu fiz para ele me bater?".

Os estudos de Mabel a fizeram compreender a relação simbiótica capitalismo-patriarcado-racismo que empurra populações inteiras para as periferias. Esta relação, atrelada à ausência de políticas públicas adequadas, está na origem da violência urbana, do desemprego à falta de creches, passando pelos inúmeros constrangimentos a que são submetidas as mulheres negras. Mabel compreendeu como ninguém este entrelaçamento perverso que faz com que as mulheres negras sejam as responsáveis pelo sustento de suas famílias. O racismo as torna pouco atraentes para os machos, que precisam desfilar com uma mulher branca para serem aceitos pela sociedade que valoriza a brancura. O patriarcado as transforma em responsáveis pela manutenção da prole. O capitalismo as coloca nos empregos mais precários e de subserviência.

Nossa rosa negra era de uma habilidade teórica e prática sem igual, como podemos perceber na análise sobre a saúde da população negra, que faz junto com outras duas Assistentes Sociais e pesquisadoras negras, Elisabete Pinto e Suely Boulos, à época atuantes da Fala Preta. De 1990 a 1996, desenvolveram o projeto "Construindo nossa cumplicidade", que possibilitou que abordassem a história emocional das mulheres negras através de grupos de autoajuda. Esta experiência, que foi apresentada e debatida no III Ciclo de Debates Racismo e Saúde Mental, em setembro de 1996, promovido pelo Núcleo de Estudo e Pesquisa Etnia, Gênero e Saúde do Programa de Saúde do Geledés, se transformou em capítulo de um dos livros sobre mulheres negras mais citados no Brasil. Organizado por Jurema Werneck, Maísa Mendonça e Evelyn White, O livro da saúde das mulheres negras: nossos passos vêm de longe, foi publicado originalmente em inglês e contou com a participação de importantes intelectuais do feminismo negro mundial, como Alice Walker, Angela Davis, Audre Lord, bell hooks e tantas outras. 


\section{Revilgto am palth}

\} MABEL ASSIS, UMA ROSA NEGRA - GONÇALVES, R.; ALMEIDA, M. S. \}

DOI: $10.12957 /$ REP.2020.47193

As referencias das feministas negras brasileiras também são das mais importantes: Conceição Evaristo, Luiza Bairros, Rosália Lemos, Edna Roland, Alzira Rufino, Sueli Carneiro são alguns dos nomes que figuram no livro.

Uma parceria que até hoje rende frutos. Como não se emocionar com uma colaboração entre mulheres negras estadunidenses e brasileiras, que colocam logo de início o compromisso com a vida, com objetivos comuns que não puderam ser destruídos pela escravidão? Evelyn White expressou assim este encontro:

O que os colonizadores não entenderam foi a profundidade de nossas alianças. Quando nos arrastaram da África para os portos do Haiti, da Jamaica, Cuba, Mississipi e Brasil, não sabiam que nossos corações separados continuariam a bater como se estivessem em um só corpo. E que nossas vozes, mesmo fraturadas, continuariam cantando em uníssono (WHITE, 2006, p. 7).

Nossa Mabel e suas companheiras de luta fizeram parte deste imenso encontro que unificava as muitas mulheres negras. Sabiam que tinham algo em comum: o fato de serem mulheres negras em uma sociedade que não reconhecia o racismo, mas que sempre tratou de forma segregada a população negra. Partiam de uma constatação: "Para nós, falar do racismo sempre foi muito difícil, seja nas universidades, nos partidos políticos ou mesmo em reuniões de família. As pessoas geralmente nos atribuem um diagnóstico: paranoia" (PINTO; BOULOS, ASSIS, 2006, p. 171). E propunham refletir sobre a saúde mental no Brasil, cujos tratamentos ou são caros ou, no sistema público, não são qualificados. Suas próprias experiências como mu-lheres negras as colocavam, no centro da questão. Ajudaram a criar grupos cuja ideia central consistia em

criar um espaço no qual nós, mulheres negras, reconstituímos nossas histórias individuais e coletivas, deflagrando um processo de autocura. A partir do momento em que conseguimos compreender nossa realidade dentro de um contexto mais amplo, percebemos que não somos culpadas por nossas dificuldades sociais e econômicas. Essa reflexão nos fortalece para enfrentarmos as difíceis situações que se apresentam cotidianamente em nossas vidas (PINTO; BOULOS, ASSIS, 2006, p. 172).

Estas experiências foram transformando a nossa rosa negra em uma referência sobre as relações étnico-raciais do ponto de vista teórico, mas também no que concerne à sua prática profissional. Conseguia mesclar com maestria a intervenção profissional com seus estudos acadêmicos. Desde 2006, atuava como Assistente Social na Prefeitura de Guarulhos, na Subsecretaria de Igualdade Racial, implementando ações de combate ao racismo. Coordenou, de 2010 a 2014, o Núcleo de Políticas Sociais Milton Santos na Universidade Guarulhos. Foi docente, de 2014 a 2015, do Programa de Pós-Graduação em Serviço Social na mesma instituição. Depois migrou 


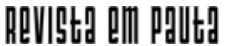

\} MABEL ASSIS, UMA ROSA NEGRA - GONÇALVES, R.; ALMEIDA, M. S. \}

DOI: $10.12957 /$ REP.2020.47193

para a Faculdade Paulista de Serviço Social (FAPSS), onde fundou e coordenou, junto com a professora Márcia Eurico, o Núcleo de Estudos e Pesquisas das Relações Étnico-Raciais Carolina Maria de Jesus.

São muitos os casos em que Mabel foi chamada para ajudar a resolver. Em outros, ela simplesmente estava lá na hora certa, no local certo, como aconteceu em um episódio envolvendo uma estudante negra da Universidade Federal de São Paulo. Ela estava no campus Baixada Santista para ministrar o seminário "A questão racial no cotidiano profissional", no âmbito da Atividade Programada Questão Racial e Serviço Social do Programa de Pós-Graduação em Serviço Social e Políticas Sociais. Encerrado o seminário, ouviu o acalorado debate de estudantes sobre racismo no campus. Sem hesitar, explicou as diferentes manifestações do racismo e a necessidade de acolhermos quem passou por esta violência.

Sua dedicação foi reconhecida pelo Grupo de Estudos e Pesquisas Intelectuais Negras, da Universidade Federal do Rio de Janeiro, que assumiu o compromisso de formular políticas capazes dar visibilidade aos saberes de Mulheres Negras, intelectuais em seus múltiplos fazeres (XAVIER, 2017). Mabel figura entre as grandes mulheres negras de diversas regiões do Brasil, que trilham o caminho da Igualdade Racial. Este reconhecimento a levou, em julho de 2017, à 15a edição da Festa Literária Internacional de Paraty (Flip), para receber uma femenagem junto com outras 180 mulheres negras brasileiras, por sua luta contra o racismo.

O Serviço Social tem muito a aprender com Mabel Assis, que escolheu ser Assistente Social para poder compreender o funcionamento das relações sociais que produzem desigualdades.

Eu fui ser Assistente Social e fui trabalhar com mulheres na periferia e nas abordagens que fazia com as mulheres, você não discute diretamente violência, você discute sexualidade, discute concepção, contracepção, como era a vida em comunidade, a forma de organização dessas muIheres, como elas se fortaleciam, como se organizavam para apoiar umas às outras, e eu discutia as violências que não iam parar nos boletins de ocorrência, eram violências que passavam pelo abuso sexual incestuoso, estupros e várias situações que elas não contavam para ninguém, e só quando esse espaço se constituía em um espaço seguro, onde elas podiam confiar (ASSIS, 2019, p. 43).

Em Mabel se podia confiar sempre. Ela entendia como ninguém o que significava a cicatriz das violências cotidianas. Vislumbrava o fim do capitalismo e a emancipação humana, mas tinha certeza de que esta não viria sem o enfrentamento, aqui e agora, do racismo e do patriarcado. Nossa rosa negra se foi, mas deixou muitas sementes para semear a primavera! 


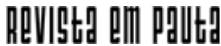

\} MABEL ASSIS, UMA ROSA NEGRA - GONÇALVES, R.; ALMEIDA, M. S. \}

DOI: $10.12957 /$ REP.2020.47193

\section{Referências}

ASSIS, M. I. de. Racismo Institucional: conversa com Mabel Assis e Márcia Eurico. Rede PUC. Gravada em 02 Jul. 2018. Disponível em: https:// www.youtube.com/watch?v=17nFbNN8dG4. Acesso em 04 dez. 2019

ASSIS, M. I. de. Diálogos entre as autoras. In: AMARO, S. (org.). O Serviço Social e o combate ao racismo: diálogos. Curitiba: Nova Práxis, p. 24-25; 42-43, 2019.

GARCIA, R. A inesquecível cartilha Caminho Suave. Veja São Paulo, 30 Ago. 2017. Disponível em: https://vejasp.abril.com.br/blog/memoria/a-ines quecivel-cartilha-caminho-suave/. Acesso em: 13 dez. 2019.

GONÇALVES, R. Quando a questão racial é o nó da questão social. Revista Katálysis, Florianópolis, v. 21, n. 3, p. 514-522, 2018.

GONZALEZ, L. Racismo e sexismo na cultura brasileira. In: Primavera para as rosas negras: Lélia Gonzalez em primeira pessoa. São Paulo: Diáspora Africana, p. 190-214, 2018.

HOOKS, B. Intelectuais negras. Revista Estudos Feministas. Rio de Janeiro, vol. 3, n. 2, p. 464-478, 1995.

MATTOSO, K. O filho da escrava (Em torno da Lei do Ventre Livre). Revista Brasileira de História. São Paulo, ano 8, n. 20, p. 37-55, 1988.

PINTO, E.; BOULOS, S.; ASSIS, M. I. de. A saúde mental da população negra: uma breve reflexão a partir da experiência com grupos de auto-ajuda. In: WERNECK, Jurema; MENDONÇA, Maísa; WHITE, Evelyn (orgs.). O livro da saúde das mulheres negras: nossos passos vêm de longe. Rio de Janeiro: Pallas/Criola, p. 171-178, 2006.

SAFFIOTI, H. O poder do macho. São Paulo: Moderna, 1987.

XAVIER, G. (org.). Catálogo Intelectuais Negras Visíveis [livro eletrônico]. Rio de Janeiro: Malê, 2017.

WHITE, E. Apresentação. In: WERNECK, J.; MENDONÇA, M.; WHITE, E. (orgs.). O livro da saúde das mulheres negras: nossos passos vêm de longe. Rio de Janeiro: Pallas/Criola, p. 7-8, 2006.

DOI: $10.12957 /$ rep.2020.47193

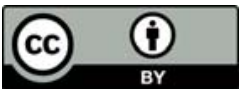

A Revista Em Pauta: Teoria Social e Realidade Contemporânea está licenciada com uma Licença Creative Commons Atribuição 4.0 Internacional. 